\title{
Características físicas de pedúnculos de clones de cajueiro-anão (Anacardium occidentale L.) produzidos em função da variação ambiental e temporal
}

\author{
Physical characteristics of cashew apples from dwarf \\ cashew (Anacardium occidentale L.) clones as a function of \\ environmental and temporal variation
}
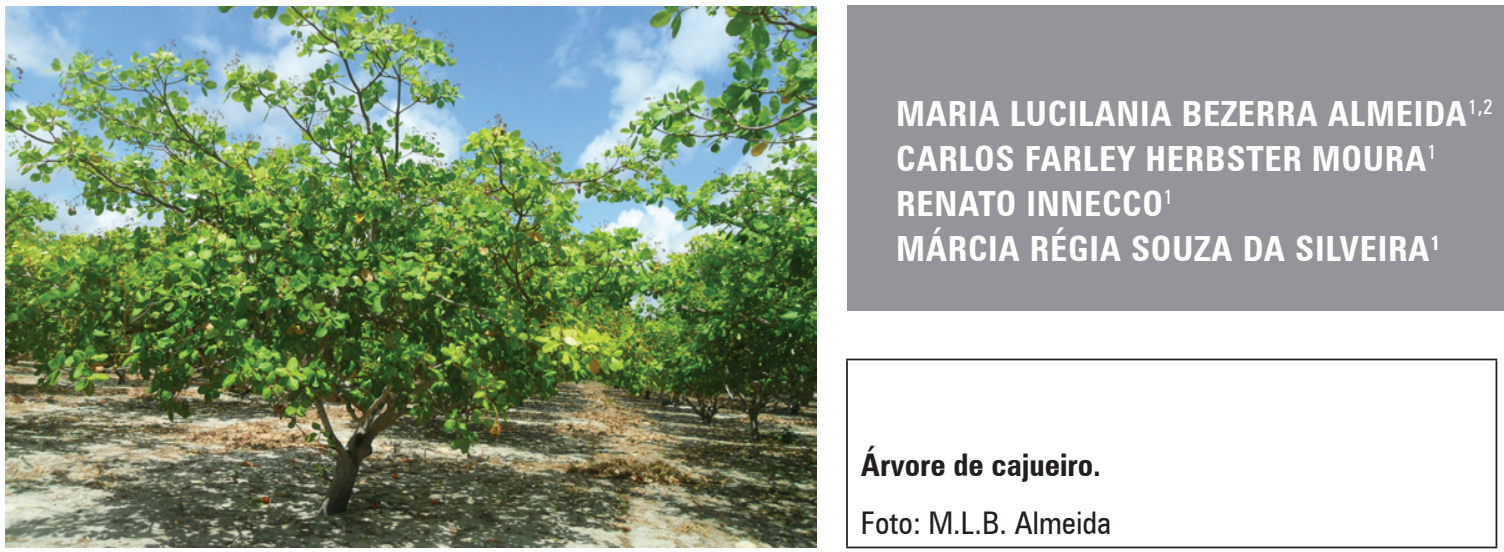

RESUMO

As variáveis de qualidade física do pedúnculo de cajueiro consistem em diferentes características externas, como aparência, tamanho, coloração, formato, firmeza, entre outros. Esses apresentam grande importância na comercialização, uma vez que são os principais atributos que atraem o consumidor no momento da compra. Diante disso, este trabalho teve por objetivo avaliar a influência da região, ano de produção e do genótipo sobre as características físicas em cajus de cajueiro-anão. $O$ delineamento experimental adotado foi inteiramente casualizado, no esquema fatorial com medida repetida no tempo, aplicando-se a técnica de confundimento, sendo três clones (CCP 09, BRS 265 e PRO 555-1) em dois locais diferentes, sertão (Alto Santo-CE) e litoral (Beberibe-CE), com quatro repetições, colhidos nos anos de 2013 e 2014. No laboratório os cajus foram avaliados quanto a massa total (castanha e pedúnculo) em (g), massa da castanha (g), massa do pedúnculo (g), comprimento $(\mathrm{mm})$, diâmetro apical e basal do pedúnculo $(\mathrm{mm})$ e firmeza do pedúnculo $(\mathrm{N})$. Observou-se que a região e o ano de produção influenciam na qualidade física do caju. Entre os clones estudados, o CCP 09 foi o único que apresentou comportamento semelhante em ambas as regiões. Isso mostra que o mesmo consegue expressar qualidade satisfatória em diferentes ambientes. Os demais apresentaram qualidade física superior quando cultivados no litoral. No sertão, o clone que se mostrou melhor adaptado foi o CCP 09, e no litoral o clone PRO 555-1.

Palavras-chave adicionais: condições ambientais, tamanho, qualidade física, precipitação pluviométrica.

Centro de Ciências Agrárias, Universidade Federal do Ceará e Embrapa Agroindústria Tropical, Fortaleza-CE (Brasil). ORCID Almeida, M.L.B.: 0000-0001-6941-3725; ORCID Moura, C.F.H.: 0000-0002-6309-509X; ORCID Innecco, R.: 0000-0002-0992-8142; ORCID Silveira, M.R.S.: 0000-0003-7959-888X

2 Autor para correspondência: lucilanialmeida@hotmail.com 


\section{ABSTRACT}

Cashew apple physical quality variables include different external characteristics, such as appearance, size, color, shape, and firmness, among others, which are very important in commercialization because they are the first characteristics perceived by consumers, who usually buy what attracts them most. The objective of this study was to evaluate the influence of the region, production year and genotype on the physical characteristics of dwarf cashew cashews (cashew apple + nut). The experiment design was completely randomized in a factorial scheme with repeated measurements over time, applying the confounding technique, with three clones (CCP 09, BRS 265 and PRO 555-1) in two different regions, sertão (Alto Santo-CE) and coast (Beberibe-CE), with four replications, collected in 2013 and 2014. In the laboratory, the cashews were evaluated for total mass (nut and cashew apple) (g), nut and cashew apple mass ( $\mathrm{g}$ ), length $(\mathrm{mm})$, apical and basal diameters of the cashew apple $(\mathrm{mm})$ and firmness of the cashew apple $(\mathrm{N})$. It was observed that the region and the production year influenced the physical quality of the cashews. Among the clones that were studied, CCP 09 was the only one that presented a similar behavior in both regions, showing that it can obtain satisfactory quality in different environments. The other clones differed, presenting superior physical quality on the coast. In the sertão region, the best adapted clone was CCP 09 and, on the coast, it was the PRO 555-1 clone.

Additional key words: environmental conditions, size, physical quality, rainfall.

Data de recepção: 30-10-2017 Aprovado para publicação: 30-01-2018

INTRODUÇÃo

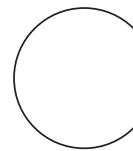

A qualidade física do pedúnculo de cajueiro consiste em diferentes características externas, como aparência, tamanho, coloração, formato, firmeza, entre outros. Estas apresentam grande importância na come Ercialização, uma vez que são os principais atributos que atraem o consumidor no momento da compra. A qualidade dos frutos é estabelecida geneticamente, assim, não havendo intervenção do homem, uma vez que a qualidade não vai além do que determina a capacidade dos genes. No entanto, para que ocorra a expressão de todo seu potencial genético, as plantas requerem condições edafoclimáticas adequadas, principalmente água e nutrientes (Aular e Natale, 2013).

Os minerais influenciam fortemente a qualidade $\mathrm{e}$ produtividades dos frutos (Wang et al., 2015). A análise química do solo permite caracterizar sua capacidade em fornecer nutrientes para as plantas, verificar a acidez e presença de elementos tóxicos, orientar as recomendações de correção e adubação do solo e escolher espécies ou variedades mais adaptadas ao cultivo (Melém Júnior et al., 2008).

O cajueiro é cultivado predominantemente em sequeiro, onde muitas vezes há uma baixa disponibilidade de água e excesso de sal. Contudo, se torna necessário, no período das chuvas, uma quantidade adequada de água à cultura, para que a planta apresente desempenho e produção satisfatórios, tendo em vista que a deficiência hídrica afeta os processos bioquímicos e fisiológicos das plantas prejudicando, assim, a sua produção (Shinozaki e Yamaguchi-Shinozaki, 2007). Em algumas espécies, o déficit hídrico durante a fase de crescimento do fruto causa drástica redução no tamanho e na qualidade dos mesmos, como observado em mandarim (Navarro et al., 2010) e em laranja doce (García-Tejero et al., 2010).

A cajucultura está concentrado nas regiões intertropicais, em que muitas vezes apresentam solo com baixa fertilidade e, por vezes, com alta salinidade. Além disso, as condições climáticas da região apresentam características específicas, como elevadas temperaturas, baixos índices pluviométricos com distribuição irregular, alta luminosidade e baixa umidade relativa, os quais influenciam o processo de evapotranspiração contribuindo para o déficit hídrico. Com isso, é possível que as diferenças ambientais e culturais entre as regiões de produção possam afetar a produção de fotoassimilados na planta e, consequentemente, a partição dos mesmos para a composição dos frutos, influenciando na qualidade física dos cajus. 
Diante disso, o objetivo do presente trabalho foi avaliar a influência da região, ano de produção e do genótipo sobre as características físicas, baseando-se na hipótese de que as diferenças edafoclimáticas entre as regiões e ano de produção possam vir a afetar a produção de fotoassimilados na planta e, consequentemente, à partição dos mesmos para a composição dos frutos, influenciando nos atributos físicos do caju.

\section{MATERIAL E MÉTODOS}

Os cajus (pedúnculo e castanha) de clones de cajueiro-anão foram provenientes de unidades demonstrativas da Embrapa Agroindústria Tropical, localizadas em dois municípios do estado do Ceará, Brasil, sendo um no sertão (Alto Santo) e o outro no litoral (Beberibe). O município de Alto Santo localiza-se na mesorregião do Jaguaribe, distante $230 \mathrm{~km}$ da capital. A unidade demonstrativa situa-se a $05^{\circ} 31^{\prime} 58^{\prime \prime} \mathrm{S}$ e $38^{\circ} 04^{\prime} 12^{\prime \prime} \mathrm{W}$, com topografia plana, $187 \mathrm{~m}$ de altitude e clima Semiárido BSh. O tipo de solo foi classificado como latossolo vermelho-amarelo e textura arenosa. O município de Beberibe está localizado a 04¹6'13" S e $38^{\circ} 06^{\prime} 05^{\prime \prime}$ W, na mesorregião do Norte Cearense, distante $79 \mathrm{~km}$ da capital com altitude de $41 \mathrm{~m}$ e clima tropical atlântico e subúmido (As). $O$ tipo de solo foi classificado como Neossolo Quartzarênico de textura arenosa.

O espaçamento de plantio constava de $6 \times 8 \mathrm{~m}$ (sistema retangular) e $7 \times 7 \mathrm{~m}$ (sistema quadrado) para Alto Santo e Beberibe, respectivamente. As plantas foram cultivadas em regime de sequeiro, sendo realizado a poda e coroamento. Os dados pluviométricos do período são apresentados na tabela 1.

O delineamento experimental adotado foi inteiramente casualizado, no esquema fatorial com medida repetida no tempo, aplicando-se a técnica de confundimento, com 4 repetições. Os tratamentos consistiam em três clones de cajueiro-anão, CCP 09, BRS 265 e PRO 555-1, as duas regiões citadas e dois anos consecutivos de produção, 2013 e 2014. O número total de plantas foi de 30 plantas por clone.

Cerca de 30 cajus maduros foram colhidos, nas primeiras horas do dia, de forma aleatória no total de plantas de cada clone, e em cada região. Em seguida, foram acondicionados em caixas plásticas com a parte inferior revestida com espuma de poliestireno de $1 \mathrm{~cm}$ de espessura, dispostos em camada única para evitar danos físicos aos pedúnculos. Os cajus foram transportados para o Laboratório de Pós-Colheita da

Tabela 1. Pluviosidade (mm) ocorrida de janeiro a dezembro de 2013 e 2014 nas regióes de Alto Santo (sertão) e Beberibe (litoral), CE.

\begin{tabular}{|l|c|c|c|c|}
\hline \multicolumn{5}{|c|}{ Pluviosidade mensal } \\
\hline Meses & Alto Santo/2013 (Sertão) & Beberibe/2013 (Litoral) & Alto Santo/2014 (Sertão) & Beberibe/2014 (Litoral) \\
\hline Janeiro & 0,7 & 61 & 7 & 38 \\
\hline Fevereiro & 56,4 & 58 & 51,6 & 125 \\
\hline Março & 27,8 & 87 & 198,2 & 190 \\
\hline Abril & 192,4 & 224 & 64,9 & 246 \\
\hline Maio & 75,4 & 88 & 0 & 145 \\
\hline Junho & 131,2 & 151 & 25,4 & 36 \\
\hline Julho & 3,2 & 22 & 0 & 0 \\
\hline Agosto & 0 & 0 & 0 & 0 \\
\hline Setembro & 0 & 0 & 0 & 8 \\
\hline Outubro & 0 & 0 & 5,2 & 5 \\
\hline Novembro & 25 & 12 & 0 & 10 \\
\hline Dezembro & 72,4 & 0 & 485,3 & 22 \\
\hline Total & 584,5 & 703 & 834,8 & 825 \\
\hline Média histórica & 834,8 & 914,1 & & 914,1 \\
\hline
\end{tabular}

Fonte: FUNCEME, 2014. 
Embrapa Agroindústria Tropical, onde passaram por um processo de seleção, sendo descartados aqueles que apresentavam pedúnculos com danos mecânicos ou atacados por pragas/doenças.

No laboratório, os cajus foram caracterizados fisicamente quanto a massa total (castanha e pedúnculo) (g), obtido por meio de balança semianalítica em cada fruto individualmente; massa da castanha (g), realizado após o descastanhamento do caju e pesagem da castanha também em balança semianalítica; massa do pedúnculo $(\mathrm{g})$ por diferença entre a massa total e a massa da castanha; comprimento, diâmetro basal (próximo a castanha) e apical (lado oposto a castanha) do pedúnculo $(\mathrm{mm})$, foram realizados com auxílio de um paquímetro digital; e firmeza do pedúnculo (N) foi determinada por meio de um penetrômetro manual Mc Cormick modelo FT 011 com ponteira de $8 \mathrm{~mm}$ de diâmetro, realizada em dois pontos, em lados opostos, na parte mediana do pedúnculo.

Para avaliar as características químicas do solo, nas áreas do experimento, foram coletados, em cada ano, amostras simples de 0 a 20 e 20 a $40 \mathrm{~cm}$ de profundidade na área de projeção da copa das plantas. Em seguida, por ocasião da homogeneidade da área, realizou-se a mistura destas para formação da amostra composta para cada região. As amostras foram armazenadas em sacos plásticos, devidamente etiquetados, e transportados para o Laboratório de Solos da Embrapa Agroindústria Tropical, onde foi peneirado e realizadas todas as análises químicas para fins de avaliação de fertilidade.

As análises seguiram metodologia de Silva (2009). Analisou-se pH (água), com leitura obtida em pHmetro; acidez potencial, $\mathrm{H}+\mathrm{Al}$ (acetato de $\mathrm{Ca}$ ), por titulação; $\mathrm{Ca}, \mathrm{Mg}$ e $\mathrm{Al}$ (KCl); $\mathrm{P}, \mathrm{K}$ e Na (Mehlich-1); Fe, $\mathrm{Zn}$ e Mn (Mehlich-1). A seguir, por meio desses, determinou-se a capacidade de troca de cátions (CTC), soma de bases (SB) e percentagem de saturação por bases $(\mathrm{V} \%)$.

Os resultados das análises físicas foram submetidos ao teste de normalidade e heterogeneidade de variância, e a análise de variância (ANOVA) foi realizada utilizando o software SISVAR versão 5.1, desenvolvido pela Universidade Federal de Lavras (Ferreira, 2008), e, para a comparação das médias, utilizou-se o teste de Tukey a 0,05 de significância. Para os dados da análise de solo, calculou-se o valor médio em cada profundidade para representação da fertilidade das áreas.

\section{RESULTADOS E DISCUSSÃO}

Por meio do teste de normalidade observou-se que os resultados obtidos, para todas as variáveis, seguiram distribuição normal, permitindo a comparação das médias, em que verificou-se a interação entre os fatores estudados para todas as características físicas avaliadas.

Observou-se na massa total interação entre clone e região, e clone e ano (Tab. 2). Para os clones nas duas regiões, verificou-se os maiores valores para o litoral, exceto o CCP 09 que não diferiu. No litoral, o clone representado por maior valor foi o PRO 555-1; já no sertão os maiores valores foram observados no CCP 09 e no PRO 555-1. Em relação aos clones em cada ano de produção, verificou-se os maiores valores no ano de 2013, exceto o BRS 265. Em 2013, a maior massa foi obtida pelo clone PRO 555-1; já em 2014 não houve diferença entre os clones.

Comportamento semelhante à massa total foi observado na massa da castanha, massa e comprimento do pedúnculo, em que observou-se as mesmas interações (clone e região; clone e ano) (Tab. 2). Para massa da castanha, observou-se as maiores massas no litoral, com os maiores valores para o PRO 555-1 em ambas as regiões. Em relação aos clones nos anos de produção, verificou-se diferença entre os anos apenas para o CCP 09, com os maiores valores no ano de 2013.

Quanto a massa do pedúnculo e seu comprimento, observou-se os maiores valores nos clones produzidos no litoral, com exceção do CCP 09. Para a massa do pedúnculo, os clones com os maiores valores foram o PRO 555-1 e o CCP 09 para região litoral e sertão, respectivamente; para o comprimento foram o PRO 555-1 e CCP 09 no sertão e PRO 555-1 no litoral (Tab. 2).

Em relação aos diferentes anos de produção, verificou-se para massa do pedúnculo os maiores valores no ano de 2013, exceto o clone BRS 265 (Tab. 2). No comprimento houve diferença entre os anos apenas para o PRO 555-1 com os maiores valores no ano de 2013. Valores superiores de comprimento do pedúnculo foram observados em estudos realizados por Lopes et al. (2011), em que verificaram 63,60 e 57,93 mm para o CCP 09 e BRS 265, respectivamente. Esta diferença com a literatura pode estar relacionado à diferenças das condições ambientais, uma vez que os dados da literatura foram obtidos de cajus produzidos 
Tabela 2. Médias das variáveis físicas de cajus (pedúnculo e castanha) de três clones de cajueiro-anão em função da variação ambiental e temporal.

\begin{tabular}{|l|c|c|c|c|c|c|}
\hline \multirow{2}{*}{ Clone } & \multicolumn{2}{|c|}{$\begin{array}{c}\text { Massa total } \\
(\mathrm{g})\end{array}$} & \multicolumn{2}{c|}{$\begin{array}{c}\text { Massa da castanha } \\
(\mathrm{g})\end{array}$} & \multicolumn{2}{c|}{$\begin{array}{c}\text { Massa do pedúnculo } \\
\text { (g) }\end{array}$} \\
\cline { 2 - 7 } & Sertão & Litoral & Sertão & Litoral & Sertão & Litoral \\
\hline CCP 09 & $73,88 \mathrm{aA} \pm 4,10$ & $70,94 \mathrm{aB} \pm 5,99$ & $6,70 \mathrm{bB} \pm 0,33$ & $8,19 \mathrm{aC} \pm 0,23$ & $67,17 \mathrm{aA} \pm 3,83$ & $62,75 \mathrm{aB} \pm 5,77$ \\
\hline BRS 265 & $51,31 \mathrm{bB} \pm 2,45$ & $83,02 \mathrm{aB} \pm 4,49$ & $6,63 \mathrm{bB} \pm 0,15$ & $10,91 \mathrm{aB} \pm 0,28$ & $44,69 \mathrm{bB} \pm 2,32$ & $72,62 \mathrm{aB} \pm 4,29$ \\
\hline PR0 555-1 & $59,54 \mathrm{bAB} \pm 3,87$ & $122,24 \mathrm{aA} \pm 9,32$ & $8,15 \mathrm{bA} \pm 0,47$ & $14,65 \mathrm{aA} \pm 0,39$ & $51,39 \mathrm{bB} \pm 3,43$ & $107,59 \mathrm{aA} \pm 9,05$ \\
\hline & 2013 & 2014 & 2013 & 2014 & 2013 & 2014 \\
\hline CCP 09 & $80,82 \mathrm{aB} \pm 4,40$ & $63,99 \mathrm{bA} \pm 3,70$ & $7,99 \mathrm{aB} \pm 0,29$ & $6,90 \mathrm{bC} \pm 0,39$ & $72,83 \mathrm{aB} \pm 4,25$ & $57,10 \mathrm{bA} \pm 3,69$ \\
\hline BRS 265 & $63,16 \mathrm{aC} \pm 4,64$ & $71,18 \mathrm{aA} \pm 8,48$ & $8,53 \mathrm{aB} \pm 0,70$ & $9,00 \mathrm{aB} \pm 0,95$ & $54,63 \mathrm{aC} \pm 4,04$ & $62,68 \mathrm{aA} \pm 7,66$ \\
\hline PR0 555-1 & $101,90 \mathrm{aA} \pm 15,50$ & $79,88 \mathrm{bA} \pm 10,38$ & $11,79 \mathrm{aA} \pm 1,24$ & $11,01 \mathrm{aA} \pm 1,35$ & $90,11 \mathrm{aA} \pm 14,30$ & $68,88 \mathrm{bA} \pm 9,09$ \\
\hline CV1 (\%) & \multicolumn{3}{|c|}{16,79} & 11,15 & & 17,48 \\
\hline CV2 (\%) & \multicolumn{3}{|c|}{17,51} & & & 19,28 \\
\hline
\end{tabular}

\begin{tabular}{|l|c|c|c|c|}
\hline \multirow{2}{*}{ Clone } & \multicolumn{4}{|c|}{ Comprimento do pedúnculo (mm) } \\
\cline { 2 - 5 } & Sertão & Litoral & $54,39 \mathrm{aB} \pm 1,34$ & $50,83 \mathrm{aA} \pm 1,26$ \\
\hline CCP 09 & $52,19 \mathrm{aA} \pm 1,69$ & $53,03 \mathrm{aB} \pm 1,17$ & $42,10 \mathrm{aC} \pm 1,28$ & $43,91 \mathrm{aB} \pm 2,64$ \\
\hline BRS 265 & $38,52 \mathrm{bB} \pm 1,02$ & $47,50 \mathrm{aC} \pm 1,43$ & $63,91 \mathrm{aA} \pm 1,83$ & $53,98 \mathrm{bA} \pm 1,78$ \\
\hline PR0 555-1 & $56,01 \mathrm{bA} \pm 2,10$ & $61,89 \mathrm{aA} \pm 2,58$ & \multicolumn{3}{|c|}{7,28} \\
\hline CV1 (\%) & \multicolumn{3}{|c|}{6,98} \\
\hline CV2 (\%) & \multicolumn{3}{|c|}{} \\
\hline
\end{tabular}

Médias seguidas da mesma letra minúscula na linha, e maiúscula na coluna não diferem entre si pelo teste de Tukey $(P \leq 0,05)$.

em Pacajus, o qual refere-se a uma região de transição entre o litoral e o sertão.

Para os diâmetros basal e apical dos pedúnculos houve interação entre clone e região, verificando as maiores dimensões nos pedúnculos provenientes da região litoral, exceto o CCP 09 que não diferiu quanto ao diâmetro basal (Tab. 3).
Em relação a firmeza do pedúnculo, observou-se interação entre clone e região e entre ano e região (Tab. $3)$. Para os clones nas diferentes regiões, verificou-se diferença apenas para o PRO 555-1 com os maiores valores mostrados no litoral. Quanto as regiões nos diferentes anos, observou-se os maiores valores no ano de 2013 para os pedúnculos produzidos no litoral, ao passo que no sertão não houve diferença.

\begin{tabular}{|c|c|c|c|c|c|c|}
\hline \multirow{2}{*}{ Clone } & \multicolumn{2}{|c|}{ Diâmetro basal (mm) } & \multicolumn{2}{|c|}{ Diâmetro apical (mm) } & \multicolumn{2}{|c|}{ Firmeza (N) } \\
\hline & Sertão & Litoral & Sertão & Litoral & Sertão & Litoral \\
\hline ССР 09 & 48,86 aA $\pm 0,87$ & $49,28 \mathrm{aB} \pm 0,95$ & $36,08 \mathrm{bA} \pm 0,86$ & $38,53 \mathrm{aB} \pm 1,09$ & $13,66 \mathrm{aB} \pm 0,31$ & $14,67 \mathrm{aB} \pm 0,65$ \\
\hline BRS 265 & $41,61 \mathrm{bB} \pm 0,71$ & $49,03 \mathrm{aB} \pm 0,87$ & $37,80 \mathrm{bA} \pm 0,43$ & 44,78 aA $\pm 0,49$ & $16,91 \mathrm{aA} \pm 0,41$ & $15,64 \mathrm{aB} \pm 1,31$ \\
\hline PRO 555-1 & $43,32 \mathrm{bB} \pm 1,09$ & $60,07 \mathrm{aA} \pm 1,69$ & $29,79 \mathrm{bB} \pm 0,80$ & $45,66 \mathrm{aA} \pm 0,42$ & $12,13 \mathrm{bB} \pm 0,46$ & $20,13 a A \pm 0,49$ \\
\hline \multicolumn{7}{|l|}{ Ano } \\
\hline 2013 & - & - & - & - & $13,75 b A \pm 0,69$ & $17,93 \mathrm{aA} \pm 0,83$ \\
\hline 2014 & - & - & - & - & $14,72 \mathrm{aA} \pm 0,63$ & $15,69 \mathrm{aB} \pm 1,06$ \\
\hline CV1 (\%) & \multicolumn{2}{|c|}{5,23} & \multicolumn{2}{|c|}{3,96} & \multicolumn{2}{|c|}{6,48} \\
\hline CV2 (\%) & \multicolumn{2}{|c|}{6,04} & \multicolumn{2}{|c|}{5,82} & \multicolumn{2}{|c|}{12,03} \\
\hline
\end{tabular}

Médias seguidas da mesma letra minúscula na linha, e maiúscula na coluna não diferem entre si pelo teste de Tukey $(P \leq 0,05)$. 
Os pedúnculos em ambas as regiões expressaram elevada firmeza, com destaque para o CCP 09, que em outros estudos aparece com valores inferiores ao do presente trabalho, como verificado por Lopes et al. (2011), que encontraram 7,77 $\mathrm{N}$ em pedúnculos produzidos em Pacajus-CE.

Na região litoral, observou-se, visivelmente, que as plantas apresentaram-se com copas bem desenvolvidas, folhosas e verdes, ou seja, eram plantas mais vigorosas, provavelmente com maior taxa fotossintética, em virtude das condições nutricionais e climáticas, proporcionadas por este ambiente, de clima tropical quente e úmido. Esse ambiente, provavelmente, permite maior expressão das atividades fisiológicas e, consequentemente, maior acúmulo de carboidratos, que resultam no incremento de biomassa, levando a produção de cajus de maior tamanho, uma vez que a quantidade de carboidratos fornecidos aos frutos depende da quantidade produzida pela fotossíntese (Léchaudel e Joas, 2007).

Por sua vez, as plantas do sertão mostraram-se com copas menos folhosas e raquíticas. Possivelmente, devido às condições do clima semiárido, quente e seco, caracterizado pelo baixo índice pluviométrico e grande irregularidade em sua distribuição, forte insolação e evaporação, temperatura média elevada e baixa umidade relativa do ar. Além disso, as condições edáficas também podem ter influenciado negativamente no estado nutricional das plantas e influenciando, consequentemente, o tamanho dos pedúnculos.

A expressão das características físicas dos cajus de cada clone depende, além da sua genética, de fatores, como o adequado atendimento as exigências nutricionais e as condições edafoclimáticas, a fim de que as plantas possam expressar todo seu potencial genético (Aular e Natale, 2013). Quanto ao crescimento do caju, esse pode ter sido afetado de forma negativa por fatores abióticos como, por exemplo, o déficit hídrico. Fato observado nos cajus (pedúnculo e castanha) do sertão, onde as plantas sofreram maior déficit hídrico, devido à menor quantidade de precipitação e, consequentemente, os cajus apresentaram redução no tamanho e massa.

Influência das condições ambientais também foi observado no desenvolvimento dos frutos de toranjeiras, quando as plantas foram submetidas ao déficit hídrico em diferentes estágios fenológicos, em que verificaram a redução do tamanho do fruto (Pérez-Pérez et al., 2014).
Os pedúnculos mais firmes quando produzidos na região litoral se deve, provavelmente, a maior quantidade de cálcio presente no solo (Tab. 4), uma vez que esse, em frutíferas, afeta a qualidade do produto final, apresentando relação direta entre o amolecimento do fruto, firmeza e tempo de vida útil pós colheita (Aular e Natale, 2013). A abundância de cálcio presente no solo litoral alcançou $82 \%$ a mais que o solo do sertão, assim, as plantas estavam sob maior disponibilidade de cálcio para absorção e assimilação e, consequentemente, maior translocação para os pedúnculos.

Além da maior quantidade de cálcio no solo litoral, a região apresenta ainda pluviosidade mais favorável a cultura, uma vez que a água desempenha papel fundamental na eficiência de aproveitamento do cálcio, visto que a maior parte do elemento é fixado pela planta via fluxo de massa. Como o vaso condutor ascendente é o xilema e a redistribuição do cálcio na planta é insignificante, quando há vários drenos envolvidos, e as folhas têm proporcionalmente maior superfície de exposição, o cálcio dirige-se, preferencialmente, a esses órgãos, em detrimento dos frutos (Aular e Natale, 2013).

Apesar das condições de solo e pluviosidade favoráveis ao aproveitamento do cálcio para formação de frutos mais firmes, o CCP 09 e o clone BRS 265 não diferiram do sertão. Isso se deve, provavelmente, a problemas como a baixa translocação de cálcio ao pedúnculo ou a não formação de complexos de pectato de cálcio no pedúnculo.

O cálcio é considerado importante para manter a estrutura da parede celular, interagindo com a pectina, para formar complexos de pectato de cálcio, que suportam a ligação entre os componentes da parede celular e reduz a atividade de enzimas associadas com a degradação da mesma (Madani et al., 2014; Khaliq et al., 2015), ajudando a manter a firmeza dos frutos.

Diante das diferentes condições edafoclimáticas das regiões de produção do cajueiro, notou-se, entre os clones estudados, que os pedúnculos do CCP 09 foram os únicos que apresentaram desempenho semelhante em ambas as regiões, exceto para o diâmetro apical. Além disso, no sertão, em que apresenta baixa fertilidade do solo, altas temperaturas, baixa precipitação pluviométrica e umidade relativa, foi o clone com maior pedúnculo, mostrando-se que consegue desenvolver seu potencial em diferentes ambientes. Podendo ainda, o CCP 09, atingir potencial superior ao do estudo realizado em outras condições 
ambientais, como observado por Lopes et al. (2011) em uma região de transição entre o litoral e o sertão, em que verificaram para massa total $141,67 \mathrm{~g}$, massa do pedúnculo de 131,56 e 10,18 g para massa da castanha. Os mesmos autores estudaram ainda o clone BRS 265, mostrando valores inferiores aos cajus produzidos na região litoral e superiores aos do sertão.

Os demais clones apresentaram grande diferença entre as regiões na maioria das variáveis analisadas, sendo essa diferença mais expressiva no clone PRO 555-1, que ainda encontra-se em fase experimental. $O$ mesmo apresentou o melhor comportamento quando produzido no litoral, sempre com valores semelhantes ou superiores aos outros clones. Isso mostra ser um clone mais apropriado para regiões de boas condições ambientais, tais como alta pluviosidade, boa fertilidade do solo, entre outros, que irão favorecer a expressão do seu potencial genético, quando comparado ao sertão, que não se observou um bom desempenho do mesmo.

Com base na análise de solo, observou-se no sertão percentagem de saturação por bases $(\mathrm{V} \%)$ menor que $50 \%$, que o caracteriza como um solo distrófico (pouco fértil), podendo ainda caracterizá-lo como um solo álico (muito pobre), uma vez que apresenta alumínio (Al) trocável $>3 \mathrm{mmol}_{c} \mathrm{dm}^{-3}$ e percentagem de saturação em alumínio ( $\mathrm{m} \%$ ) superior a $50 \%$ (dados não apresentados). Isso significa que existe uma maior adsorção de $\mathrm{Al}^{3+}$ e $\mathrm{H}^{+}$e quantidades menores dos cátions básicos $\mathrm{Ca}^{2+}, \mathrm{Mg}^{2+} \mathrm{e} \mathrm{K}^{+}$, adsorvidos nos coloides do solo (Ronquim, 2010), que o caracteriza como um solo ácido, podendo comprovar pelos valores de $\mathrm{pH}$, que variaram de 4,43 a 5,06, abaixo do pH ideal à cultura (Tab. 4).

A maioria das culturas apresentam boa produtividade quando no solo é obtido valor de V\% entre 50 a $80 \%$ e valor de $\mathrm{pH}$ entre 6,0 e 6,5 (Ronquim, 2010). Fato observado no solo litoral, em que observou-se um V\% superior a $70 \%$, em ambos os anos e profundidades de coleta, e pH variando de 6,13 a 6,78, considerado como um solo eutrófico (fértil), o que, provavelmente, proporcionou a produção de cajus com atributos físicos superiores aos do sertão.

Diante disso, a quantidade de alumínio presente no solo do sertão (5 a $12 \mathrm{mmol}_{c} \mathrm{dm}^{-3}$, variando de acordo com a profundidade de coleta da amostra de solo) pode ter comprometido a assimilação dos nutrientes pelas raízes, prejudicando o bom desempenho das plantas e, consequentemente, a qualidade no aspecto

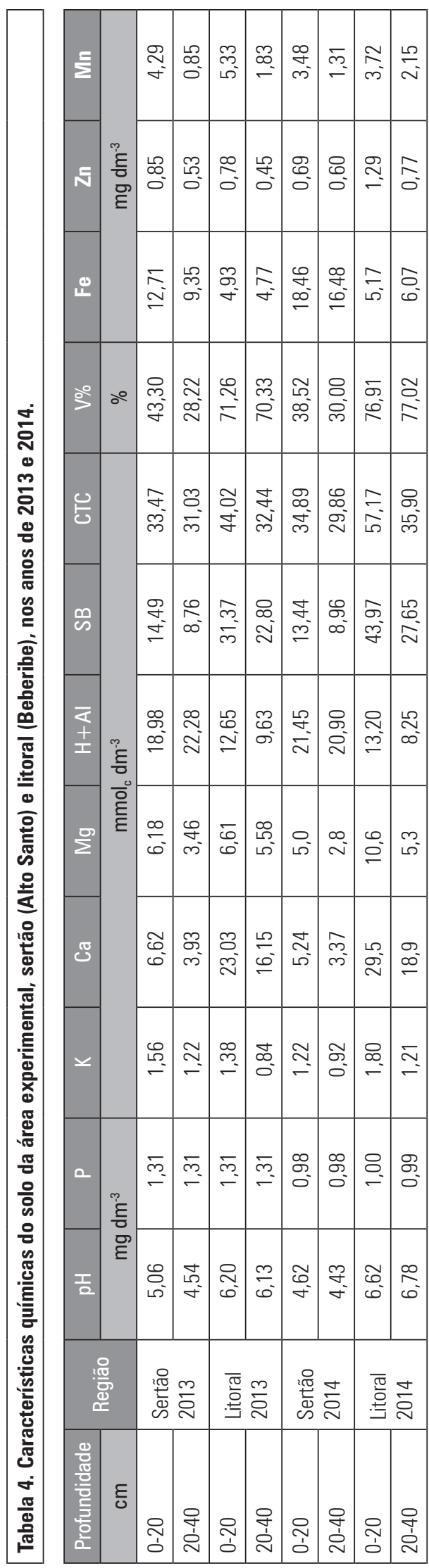


físico dos pedúnculos, uma vez que a acidez do solo vinculado ao excesso de alumínio e ferro restringe a absorção de água e nutrientes pela planta, devido a efeitos osmóticos induzidos pelo excesso da concentração de sais no solo (Prado, 2012). No entanto, o CCP 09, provavelmente, mostrou-se mais resistente a essas condições extremas, conseguindo explorar solos mais ácidos e apresentar desempenho semelhante ao litoral.

Quanto aos dados pluviométricos dos anos de 2013 e 2014, fornecidos pela FUNCEME (2014, 2015) (Tab. 1), observou-se que a região do sertão choveu abaixo da média histórica. Além disso, ainda apresentou uma redução de $99,2 \mathrm{~mm}$ do ano de 2013 para 2014. No litoral, as chuvas também ficaram abaixo da média histórica, porém dentro da faixa adequada ao cultivo do cajueiro, que varia entre 800 a $1.500 \mathrm{~mm}$ por ano. Apresentou um aumento de $122 \mathrm{~mm}$ do ano de 2013 para o ano de 2014.

Com isso, nota-se que o valor mínimo exigido pela cultura só foi atingido pela região litoral no ano de 2014, apresentando $340 \mathrm{~mm}$ de diferença do sertão. Com a pluviosidade abaixo da média exigida pela cultura, ocorre um déficit hídrico, levando a redução da extração de nutrientes do solo, limitando a solubilização dos mesmos no ambiente das raízes e alterando a morfologia do sistema radicular (Alves et al., 2013). Afetando ainda o desempenho produtivo, provavelmente, por meio da redução do processo fotossintético, devido a menor folhagem da copa, assim, há uma menor quantidade de carboidratos e, consequentemente, afetando negativamente na produção e qualidade física dos cajus.

\section{CONCLUSÕES}

A região, o ano de produção e o genótipo influenciam a qualidade física de pedúnculos de cajus. Entre os materiais estudados, o CCP 09 foi o único que apresentou desempenho semelhante em ambas as regiões. Isso mostra que o mesmo consegue expressar qualidade satisfatória em diferentes ambientes; os demais diferiram, apresentando qualidade física superior para a região litoral. Na região do sertão, o material com melhor desempenho foi o CCP 09, e no litoral o clone PRO 555-1.

Conflito de interesses: o manuscrito foi preparado e revisado com a participação de todos os autores, que declaram não ter qualquer conflito de interesses que possa afetar a validade dos resultados do trabalho apresentado.

\section{REFERÊNCIAS BIBLIOGRÁFICAS}

Alves, E.S., J.E. Cardoso, L.G.C. Silva e J.S. Lima. 2013. Interação das condições edafoclimáticas com a resinose do cajueiro. Enciclopédia Biosfera 9(16), 1320-1345.

Aular, J. e W. Natale. 2013. Nutrição mineral e qualidade do fruto de algumas frutíferas tropicais: goiabeira, mangueira, bananeira e mamoeiro. Rev. Bras. Frutic. 35 (4), 1214-1231. Doi: 10.1590/S0100-29452013000400033

Ferreira, D.F. 2008. Sisvar: um programa para análises e ensino de estatística. Rev. Symposium 6(2), 36- 41.

FUNCEME (Fundação Cearense de Meteorologia e Recursos Hídricos). 2014. Calendário das chuvas no estado do Ceará. Em: http://www.funceme.br/index.php/ areas/tempo/calendariodaschuvas; acessado em janeiro de 2014.

FUNCEME (Fundação Cearense de Meteorologia e Recursos Hídricos). 2015. Calendário das chuvas no estado do Ceará. Em: http://www.funceme.br/index.php/ areas/tempo/calendariodaschuvas; acessado em janeiro de 2015 .

García-Tejero, I., R. Romero-Vicente, J.A. Jiménez-Bocanegra, G. Martínez-García, V.H. Durán-Zuazo e J.L. Muriel-Fernández. 2010. Response of citrus trees to deficit irrigation during different phenological periods in relation to yield, fruit quality, and water productivity. Agric. Water Manag. 97 (5), 689-699. Doi: 10.1016/j.agwat.2009.12.012

Khaliq, G., M.T.M. Mohamed, A. Ali, P. Ding e H.M. Ghazali. 2015. Effect of gum arabic coating combined with calcium chloride on physico-chemical and qualitative properties of mango (Mangifera indica L.) fruit during low temperature storage. Sci. Hortic. 190, 187-194. Doi: 10.1016/j.scienta.2015.04.020

Léchaudel, M. e J. Joas. 2007. An overview of preharvest factors influencing mango fruit growth, quality and postharvest behaviour. Braz. J. Plant Physiol. 19 (4), 287-298. Doi: 10.1590/S1677-04202007000400004

Lopes, M.M.A., C.F.H. Moura, F.A.Z. Aragão, T.G. Cardoso e J. Enéas Filho. 2011. Caracterização física de pedúnculos de clones de cajueiro anão precoce em diferentes estádios de maturação. Rev. Cienc. Agron. 42(4), 914 920. Doi: 10.1590/S1806-66902011000400013

Madani, B., M.T.M. Mohamed, C.B. Watkins, J. Kadir, Y. Awang e T.R. Shojaei. 2014. Prehavest calcium chloride sprays affect ripening of Eksotika II' papaya fruits during cold storage. Sci. Hortic. 171, 6-13. Doi: 10.1016/j.scienta.2014.03.032 
Melém Júnior, N.J., I.C.B. Fonseca, O.R. Brito, T. Decaëns, M.M. Carneiro, M.F.A. Matos, M.C. Guedes, J.A.L. Queiroz e K.O. Barroso. 2008. Análise de componentes principais para avaliação de resultados analíticos da fertilidade de solos do Amapá. Semina Ciênc. Agrár. 29 (3), 499-506.

Navarro, J.M., J.G. Pérez-Pérez, P. Romero e P. Botía. 2010. Analysis of the changes in quality in mandarin fruit, produced by deficit irrigation treatments. Food Chem. 119 (4), 1591-1596. Doi: 10.1016/j. foodchem.2009.09.0488

Pérez-Pérez, J.G., J.M. Robles e P. Botía. 2014. Effects of deficit irrigation in different fruit growth stages on 'Star Ruby' grapefruit trees in semi-arid conditions. Agric. Water Manag. 133, 44-54. Doi: 10.1016/j. agwat.2013.11.002

Prado, R.M. 2012. Nutrição de plantas: Diagnose foliar em frutíferas. Gráfica Multipress Ltda., Jaboticabal-SP, Brasil.
Ronquim, C.C. 2010. Conceitos de fertilidade do solo e manejo adequado para as regiões tropicais. Embrapa Monitoramento por Satélite. Boletim de Pesquisa e Desenvolvimento 8.

Shinozaki, K. e K. Yamaguchi-Shinozaki. 2007. Gene networks involved in drought stress response and tolerance. J. Exp. Bot. 58, 221-227. Doi: 10.1093/jxb/ erl164

Silva, F.C. 2009. Manual de análises químicas de solos, plantas e fertilizantes. 2. ed. EMBRAPA, Brasília, Brasil.

Wang, G., X.Z. Zhang, Y. Wang, X. Xu e Z. Han. 2015. Key minerals influencing apple quality in Chinese orchard identified by nutritional diagnosis of leaf and soil analysis. J. Integr. Agric. 14(5), 864-874. Doi: 10.1016/ S2095-3119(14)60877-7 